Commentary:

\title{
Braced for Impact: Architectural Praxis in a Post-Pandemic Society
}

\author{
Dr. Sapna Papu \\ Director and Professor \\ BMS School of Architecture, Bangalore
}

\section{Shreyasi Pal}

Associate Professor

BMS School of Architecture, Bangalore

Abstract

Our systematic neglect of universal human needs of shelter, health and safety is set to make the poorer sections disproportionately more vulnerable to the COVID-19 pandemic which the whole world is now struggling to contain. Architecture must carry a burden of guilt as present configurations of urban built environment normalise socio-spatial injustice and perpetuate capitalist fictions. Here, we interrogate how architecture can reclaim its social relevance, particularly in cities of the Global South, when the post-pandemic society adopts more socio-environmentally sustainable, 'new normal' lifestyles to build community resilience.

Keywords

COVID-19, pandemic, architecture, 'new normal', resilience, social justice, spatial justice

\section{An Existential Moment}

Bleak statistics quantifying global human suffering and eerie photographs of desolate urban spaces, confront us daily as the world struggles to contain the COVID-19 pandemic. Geographically distant 'developed' and 'developing' economies function too closely today in a world flattened by global engines of capitalist growth. Experts had warned us, repeatedly, that unchecked socioenvironmental exploitations lead to instabilities across local and global territorial scales. In denial, we have rejoiced in overconsumption and accumulation of wealth, resources and 'surplus value'. Our systematic neglect of universal human needs of shelter, health and safety is set to make the poorer sections disproportionately more vulnerable. Public healthcare infrastructures and welfare systems are stretched to the limit in every nation, putting us in the throes of a historic global tragedy. We witnessed how the nation-wide lockdown in India left thousands of poor migrant workers, helpless and stranded in the capital city of Delhi. Desperate, broke and hungry, these men, women and children undertook precarious journeys on foot to reach their villages hundreds of kilometres away. The uncanny feeling of being part of an apocalyptic fiction would likely stay with us for long.

The contagion has forced our busy, urban lives to a standstill as we observe mandatory lockdowns. We could make the best use of these rare moments of pause to acknowledge, not just the fragility of our economies but the gaping inequalities in our social ecologies. The crisis has exposed a burden of guilt that we must all shoulder. Every discipline should retrace its steps and ascertain disciplinary accountability towards this global social and moral crisis. This disruption has lent us a brief window of opportunity to make amends and with equal parts of excitement and anxiety, the discipline of architecture is set to step into the post-pandemic world. Below is a modest epistemological exercise on the disciplinary intent of architecture, meant to reclaim social relevance of the profession.

\section{The 'New Normal'}

As we find ways to cope with the socio-economic repercussions of the pandemic, architecture would have to continually reinvent itself, almost in real time. Before we speculate on how architecture would perform its disciplinary duties, one has to make informed conjectures to qualify the 'new 
normal'. Let us clarify, that it is not the lockdown, the temporary curtailing of personal liberties like movement restrictions, social distancing etc that we focus on here, but the fundamental ways this crisis might have upended our way of life for the foreseeable future.

Ethical obligations suggest that we drastically change how we live, work, play, how our children get education, how the elderly and the sick get care, how we consume resources from food, clothes and shelter to travel, leisure and entertainment. As individuals, the 'new normal' society may expect us to adopt more socio-environmentally sensitive lifestyles, so that our small measures add up to larger community well-being. Sustainability and community resilience, in global socio-economicenvironmental terms, seem to be the only surviving logic in these surreal circumstances.

Discussions about urban futures often centre around 'smart' cities integrated with digital technologies. Then again, like with the ever-widening rich-poor divide, the 'digital divide' would create very different realities for different sections of our society. The sudden lockdown has interrupted our routines and many of us have had to quickly adopt to remote working and online learning. This is however true only for the few of us who are fortunate enough to be digitally connected or happen to have professions where we could be, at least partially, productive from remote locations. To put our privilege in perspective, only about half of the population of India can even access the internet, which is a better figure than most of the developing world.

Hopefully, the value ascribed to an ordinary human life is set to be reappraised. For better or for worse, the worldwide spread of the deadly virus has revealed that safety bubbles around the relatively powerful are not impenetrable. Economic class, creed, race, gender, religion, ethnicity and even nationality cannot secure immunity from suffering in case of a global disaster. Biological vulnerability could prove to be a great leveller.

Historically, human suffering in global crisis situations have never increased co-operation among nations. Social scientists might be able to predict how international geopolitics is set to reshuffle power in response to the disruption in global economic activity. Citizens now are expecting governments to reduce future vulnerabilities and plan for periods of economic self-isolation. Without the incentive to protect shared gains from multi-country production chains, countries would perhaps reinforce their local supply and distribution chains and promote responsible consumption. If decoupling from global capitalist engines is not an option, countries that host service industries or provide cheap human labour must work towards universal social programs and robust public infrastructure. The 'political society' has failed to successfully negotiate adequate resource allocation and competent governance from neo-liberal administrations (Chatterjee 2013) (Prashad 2020). The global community, ideally, must invest in public infrastructure- housing, education, health and sanitation, especially in the cities in the Global South where conditions of poverty, population density and extensive socio-cultural injustice have been amplified by uneven resource allocations to corporate interests and patchwork urban management systems.

Nelson Mandela is popularly credited with the quote that 'It always seems impossible until it's done'. We must consciously stop being accessories to power structures to create a more egalitarian society. Our sense of comfort with the status quo and individualistic 'each man for himself' habits have cemented our current irresponsible lifestyles. We would need a thorough social reconditioning to adopt to this 'new normal'- as families, communities, organisations and nations. Built environment, and in turn, architecture, can play a socially transformative role in helping us unlearn the ways in which we are set, by enabling us to live our 'new normal' lives in responsibly designed houses, workplaces, neighbourhoods and cities. 


\section{The Scope of Architecture}

\section{Disease Control and Disaster Mitigation through Architecture}

How our cities are shaped today- the street grids, sewage systems, zoning laws- bear testimony to how architecture and urban planning have incorporated concerns of public health, historically, in response to urban squalor and recurring cholera, flu and tuberculosis epidemics. In the next few years, we can expect increased disciplinary deliberations on disease prevention and disaster mitigation. There are well established protocols as well as a wealth of research on how to minimize infectious disease transmission through mediations in built environment. It is likely that recent experiences would enrich existing research with more data, generating even more refined models from which revised recommendations could emerge. Social distancing norms are but contingent measures which cannot continue indefinitely, given our urban densities, cultural inclinations and the fundamental human need for social connection. The pandemic has brought about some knee-jerk responses. Disinfecting chambers, temperature screening at entrances, wider corridors and staircases, more openable windows, antibacterial fixtures and finishes, self-cleaning toilets are a few of such measures. Also, existing technologies of facial recognition, motion-sensor and touch-less, voice-activated fixtures-automatic doors, elevators, light switches and temperature controls are set to find wider application. Advances in computing, telecommunications and remote sensing could be better integrated in smart city networks. Urban recovery plans dependent on real-time data sharing could result in faster response time and better prevention, monitoring, management and containment.

Architectural and planning decisions can reduce human suffering to a large extent in case of natural as well as man-made disasters. Our discussion below is not about the role of architecture with respect to disease control and disaster management but a broader critique of the agency of architecture. We interrogate the readiness of the profession to cater to a utopian, post-pandemic 'new normal' society which prioritises sustainable resource consumption, moderates global corporate greed to achieve community resilience.

\section{Can architecture be held accountable?}

One can legitimately ask if implicating architecture is fair. We cannot be expected to change the forces of socio-economic production which decide who get to be our paymasters. Architectural creations are not literary social critiques or artistic whimsies stirred up in studios but negotiated in the real-world with every design decision carefully weighed on economic merits. If dominant political and corporate powers decide our design briefs, then how, if at all, could we be held accountable for the socio-spatial injustice around us? And how could we do things differently?

\section{Architectural Semiotics and the 'colonisation of everyday life' by capital}

Contemporary culture is about free flow of visuals and T J Clark has warned us about the manipulations of compressed pseudo-narratives of images (Clark 1999). The omnipresence of architectural 'images of efficiency' normalises socio-spatial injustice and makes us indifferent to widening social inequality (Mehrotra 2011). It is bizarre how we have let unimaginable squalor to continue in urban slums while neo-liberal administration has facilitated the construction of skyscrapers, grandiose airports, luxury malls and hotels as odes to capitalism and corporate power. In the National Capital Territory of Delhi, the Central Government is set to invest obscene amounts of money in the Central Vista redevelopment project which reimagines Lutyens' Delhi, while recent estimates suggest that twenty to fifty percent of Delhi's population currently live in slums in appalling living conditions (Abhijit Banerjee 2012). 
Rancière (2004) has talked about the politics of aesthetics and the 'distribution of the sensible' propagating hegemonic fiction through control of what is visible in the public realm. Design magazines and popular architecture shows on television and other digital visual media valorise glamourous lifestyles in extravagant buildings and shape popular aspiration for a 'good life'. We still aspire for an outdated modern architectural vocabulary in which fantastic city skylines and mathematically planned neighbourhoods were produced in the West in the middle of the twentieth century. In recent years, neoliberal governments have reproduced these models as dystopian pockets in our Global South cities. It is now normal to expect series of serpentine flyovers, like that we find in Hyderabad and Bangalore, to connect our swanky new airports to the multinational hubs of corporate towers, bypassing the inconvenient sights of urban blight. Our post-truth society consumes these capitalist fictions as they are perpetuated through prominent architectural visual signs that promise tangible ways for us to be closer to an ever-distant 'first world' experience ( $\mathrm{Pal}$ and Oommen 2015).

\section{Beyond Star-rated Green Buildings: Architecture as an ethical process and product}

Public awareness of critical architectural practice is mostly limited to the signature styles of a few celebrated architects who engaged with the informal and ground-up building traditions as aesthetic exercises in their personal search for 'critical regionalism' (Frampton 1984). Green building practices currently find limited application only in high-end architectural products, typically in 'lifestyle apartments' and corporate hubs. Humane design of urban built environment can be undertaken only when a large percentage of the population is on board with the idea and aspires for sustainable mode of living. For example, projects like Delhi Bus Rapid Transit System which failed to educate the public of its intent, faced a lot of initial opposition from the middle-class who were attached to the idea of private car ownership. As our cities strive to be global, public opinion still leans heavily towards a typical International Style architectural aesthetic.

The first patrons of modern architecture were a few 'woke' individuals who played a historically important role of promoting a disturbingly austere, a-historical modern architectural vocabulary as they were invested in modernism's project of transforming society. Architecture responded readily by churning out shiny new prototypes, innovative in use of technology, clean of historical reference and functional with almost mathematical precision. Even now, some of our clients, when convinced of the social merits of more responsible ways of shaping our built environment, may open up to the idea of being pioneering patrons of a new architectural vocabulary. There is already some increased awareness of how individual consumption pattern can mitigate the ill-effects of systematic exploitation. We now see many businesses, self-regulate and adopt an ethical framework to balance the trade-offs between profit margin and the welfare of people and environment. We are now familiar with product eco-labels and green stickers like 'Fairtrade', 'Ecomark', 'Energy stars' etc which enable consumers to make informed decisions. Architecture should be ready to actively disseminate ideas of sustainable living as an attractive alternative. Only when sustainable lifestyle is glamourized and popularised through persistent public discourse construction could the planning and design of our cities change quickly and drastically.

\section{Role of architecture in post-crisis social reconstruction}

In the 'new normal' when we increasingly work from a remote location, learn and upgrade skills online, get medical opinion online and shop for necessities from e-commerce sites, we reduce the need of brick and mortar buildings- offices, schools, colleges, clinics and shopping centres- to that of virtual digital space, accessed from devices like laptops and smartphones. If we build less, architecture can remain relevant only by revisiting our professional intent. 
First of all, we could dissuade ideas to build more and promote retro-fitting practices to increase life and functionality of existing city fabric. We have been building too much without much thought about maximising the potential usage of the resources already utilised. One can imagine building regulations in the future optimising return of material and labour investment by allowing only for flexible, multifunctional and mixed-use function in large public projects. Large public expenditures like stadiums, cultural centres, business parks and convention centres, could be deliberately designed to double up as doomsday infrastructure. Meanwhile, we could push for our private projects to be flexible in design so as to be able to augment critical public infrastructure as part of their corporate social responsibility. Drawing inputs from the sub-discipline of building conservation, old buildings could be maintained, retrofitted and repurposed to last years beyond their intended life-span, and not readily subjected to urban renewal. The historical shift to RCC buildings was to make quick and durable construction accessible for the masses but today we know of their high carbon footprint. We could move to zero waste buildings in cases where finances permit or maximise the reuse of buildings materials salvaged from old buildings, within safety parameters. Careful micro-decisions about material choice, detailing and specification can minimise wastage. Instead of cosmetic city beautification programs, regulatory framework could mandate that urban infrastructure like flyovers, bridges, public transit hubs, are designed as multipurpose public areas accommodating socio-spatial needs of the informal sectors, adding economic value to all the usual leftover 'lost spaces' (Trancik 1986). In keeping with urban design best practices, we could aim to educate the public of benefits of equitable redistribution of road space, prioritising pedestrians and non-motorised transport. We could reinforce the green networks of our cities with carefully planned urban forestry which could increase urban bio-diversity in due course. We could reduce paving, increase percolation and design urban landscape proposals with local fruit trees, herb gardens to reinforce local food supply chains or a selection of native species to encourage bio-diversity, instead of energy-intensive water features, manicured lawns and exotic, and often predatory, plant species.

We could rethink the common architectural typologies. The shelter for family life is the primordial architectural space. Public housing in any city are vertical stacks of boxes, with very low quality of life. The city of Mumbai has one of the highest cost-of-living indexes in the world but is also home to Asia's largest slum Dharavi. The spread of the contagion in Dharavi has the potential to endanger even the uber rich, housed in the gated luxury condominiums of Mumbai. The conditions of overcrowding among the urban poor make social distancing almost impossible to implement (Khan and Abraham 2020). Deplorable living conditions, dependence on community toilets increase their chances of exposure and limited access to healthcare make recovery and containment problematic. Such urban pockets of deprivation are common to all Global South cities and have emerged as sites of human suffering or if the pandemic worsens, as potential loci of civil unrest. Administrative initiatives to address the problem of public housing for the urban poor reduce complex dynamics of socio-economic networks of slums to a mathematical spatial problem, which are usually resolved insensitively, producing a variety of unsuccessful projects.

At the other end of the housing spectrum we have a huge surplus of empty luxury apartments, built to park investments for affluent classes. The mid-range affordable housing sector continues to replicate the high-rise apartments first envisaged post WWII. These context-free outdated urban fixtures add little value to quality of urban life. Those among us fortunate enough to have a roof over our heads while observing social distancing recommendations, complain that an average apartment is not flexible enough to be reconfigured and cannot accommodate home offices or children activity rooms. Most apartments lack kitchen gardens and big enough balconies where we could grow some fresh produce or sit in the sun. We could reimagine all housing complexes as resilient, self-contained neighbourhoods, making smart use of materials and technology, with radically different building forms, use of solar panels, turbines and intelligent facades, community gardens and urban farming, 
rain water harvesting, bio-swales and other sustainable drainage systems, garbage sorting, composting and recycling systems, and social infrastructure like retails, playschools, gyms, clinics and jogging tracks. To accommodate 'work from home' situations, we could even revisit old residential typologies in which it was common to have shops or workspaces adjoining private family quarters. There is a vast range of fantastic options, explored as wishful academic exercises that we could tap into. While societies across the globe have invested in privatization, gated communities and electronic surveillance, very few innovative housing projects promoting local self-sufficiency and community resilience have been realized for want of socio-economic viability or possibly, public awareness and an informed value-system.

The air-conditioned shopping mall has become a proxy for public space in our cities. As more and more commercial establishments align themselves to e-commerce models, the shopping malls may eventually lose their aspirational value. As we reinforce local supply chains, we would have to remodel traditional market places and accommodate the needs of informal retail sector in mixed use neighbourhoods. As remote working becomes the new norm, a significant percentage of workers in corporate jobs, software technology, education etc may continue to work from home. Office design models like co-working spaces, open plans or individual cubicles may be replaced with wellventilated spaces with reduced occupancy, and spacious meeting spaces to help foster meaningful collaboration and innovation among employees. Most workers in manufacturing, retail, construction, entertainment, hospitality and transportation would continue to depend on brick and mortar spaces which would need to be retrofitted to limit loss of life and property during any future crisis.

Here, we are not advocating for any particular of the above, but for a critical epistemic approach in place of habitual architectural practice. Architecture speaks a visual language and implicitly signifies systematic socio-spatial injustice. It is within the scope of our profession to internalise objectives of sustainability, safety and social good and self-regulate our professional code of conduct to remain socially relevant.

\section{Architectural Research, Education and Pedagogy}

As we step back and critically re-evaluate our work, we realize that a deep restructuring has to begin with a reimagining of the education and training of future architects. Given that most developing countries followed Western models of professional education, globally most architectural schools share a similar teaching framework. Architectural students are currently instructed in design principles, history- theory- criticism, social studies, sustainability practices, digital architecture besides the technicalities of structural systems, materials and methods of construction, through classroom lectures, tutorials, studio sessions and a compulsory internship. The domain of research in architecture operates like a multiverse, where there are numerous established schools of thought dealing with the specifics of their specialities, establishing transdisciplinary dialogues from diverse disciplines ranging from computer science, Al to the critical social sciences. We are confident when we say that all of the technological and social inadequacies, we are set to address have been partially resolved through research.

In the short term, the focus of academic discussions might be on public health maintenance and disaster mitigation through architecture. Towards the larger goal of establishing community resilience through architecture, we posit that students should engage in immersion models and grounded research with marginalized communities. They should be trained to navigate through existing research from across the architectural sub-disciplines. Students also need to be updated in key technological and digital innovations so as to be able to seamlessly integrate smart technologies. The end goal would be to cultivate a critical investigative outlook which could prevent succumbing to 
popular trends without ethical introspection. Architectural theories articulate how the discipline has reconfigured its fundamental paradigms, in response to contextual social stimulus. Architects need to be deeply aware of these theoretical standpoints, particularly now, as our contemporary practice is interrogated on grounds of social validity.

Renewed focus on remote learning might lead to surprising innovations in the field of architectural education. 'One size fits all' approaches, outmoded classroom-based lectures, entrenched institutional biases, and institutionally-controlled access to knowledge production and dissemination may give way to more open-mindedness and flexibility in terms of pedagogical approach, assessment protocols and collaborative methods of teaching and research that blur disciplinary boundaries. Diverse stakeholders, including faculty, administrators, governments, private and public technology providers would have to collaborate to reduce the 'digital divide.' Institutions may become more comfortable in seeking out and employing remotely located local researchers as well as international niche experts. Improved access to digital archives and remote learning resources could make inter-disciplinary and transdisciplinary knowledge production easier. And as architects we must note that in this re-imagined world, the institute website, more than the physical buildings, become portals to knowledge.

\section{Disciplinary Obligations}

Historically architecture has never been apolitical. Only what is termed cognitive dissonance might have made us ignore and even deny any evidence of ideological corruption of our profession for so long. Traditionally, architecture is conceived to be a utilitarian and often a stylistic practice, with an ambition of transformative socio-political agency. Modern architectural practice is widely read and criticised today as an instrument of capitalist violence (Pal and Oommen 2015). Professionally we still aspire to build egoistic landmarks, more often than not, glorifying capital, ignoring broader social and moral commitments and putting 'man over nature'. Built space is socially produced but is also the vehicle through which systems of social injustice are performed and perpetuated. The postpandemic utopia has a wishful abundance of moral awareness, harmony with nature, grassroot empowerment and technological smartness. And the ambitious projection is that architecture and related disciplines could produce a just city, by prioritising socio-spatial justice as its primary disciplinary intent.

We cannot wait for the world to change for the better because we have played a role in shaping this unjust world, every time we accommodated the unjust wants of our corporate clients, real estate developers and neo-liberal city authorities. We are required to envisage an alternate future for our cities and initiate public discourse on how community resilience can be realized through socially responsible, adaptable and sustainable built environment. The best way to communicate would be to produce and publicize attractive images of sustainable lifestyle. New architectural prototypes, based on rigorous research, could be packaged as ethical products which informed consumers could make a moral choice to invest in.

Our contribution to the 'new normal' society could begin with simply saying firm 'no'-s multiple times during the course of our ordinary days. We cannot allow ourselves to return to a prepandemic 'normality' and continue to build the same type of buildings or teach the same syllabi or instruct classes with the same teaching goals. As creative individuals, our 'self-actualization' needs at the top of Maslow's pyramid (1943) are realized through our signature architectural expressions. Exhortations and appeals would work only if the architecture community reaches a consensus and recalibrates the criteria of personal and professional success in the field along moral and ethical scales. 


\section{References}

Abhijit Banerjee, Rohini Pande, Michael Walton. 2012. (Working Paper) Delhi's SlumDwellers: Deprivation, Preferences and Political Engagement among the Urban Poor. International Growth Centre, LSE.

Chatterjee, Partha. 2013. Lineages of Political Society: Studies in Postcolonial Democracy. Columbia University Press.

Clark, T J. 1999. The Painting of Modern Life: Paris in the art of Manet and his followers. Princeton: Princeton University Press.

Forty, Adrian. 1992. Objects of Desire: Design and Society since 1750. Thames and Hudson: London.

Frampton, Kenneth. 1984. "Towards a Critical Regionalism: Six points towards an architecture of resistance." In Anti Aesthetic:Essays on Postmodern Culture, by Hal Foster, 16-30. Seattle: Bay Press.

Maslow, A. H. 1943. "A theory of human motivation." Psychological Review 370-396.

Mehrotra, Rahul. 2011. Architecture in India: Since 1900. Pictor.

Mohd Imran Khan, Anu Abraham. 2020. "No 'Room' for Social Distancing: A Look at India's Housing and Sanitation Conditions." Economic and Political Weekly Engage 55 (16).

Prashad, Vijay. 2020. "A Socialist Cry for Civilisational Change: COVID-19 and the Failure of Neo-liberalism." Economic and Political Weekly Engage 55 (16).

Rancière, Jacques. 2004. The Politics of Aesthetics. London: Continuum International Publishing.

Shreyasi Pal, Thomas Oommen. 2015. "Politics of Architecture." Economic and Political Weekly 50 (14).

Trancik, Roger. 1986. Finding Lost Space: Theories of Urban Design. John Wiley \& Sons. 